\title{
Circulating rotavirus $G$ and $P$ strains post rotavirus vaccination in Eastern Mediterranean Region
}

Shaia S. R. Almalki, MSc, PhD.

\begin{abstract}
الأهداف : الكشف عن التغيرات في سلالات الروتا وتوزيعها في إقليم

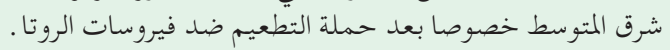

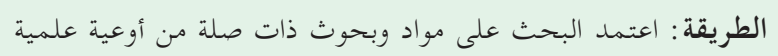

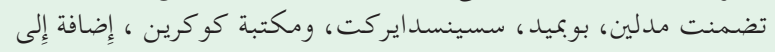

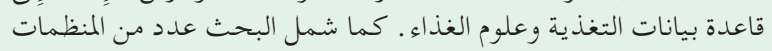

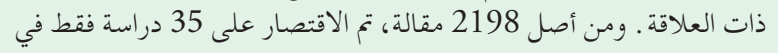

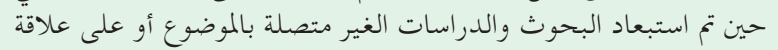

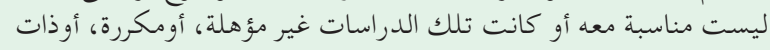
جودة منخفضة. النتائج : أفادت 30 دراسة سابقة لتطبيق برامج التطعيم عن عدوى سلالات

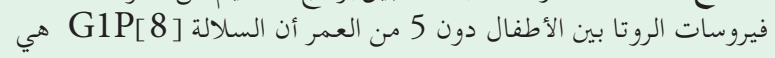

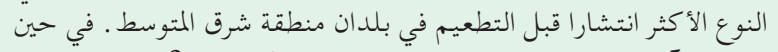

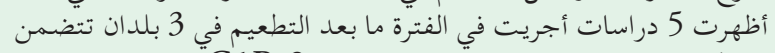

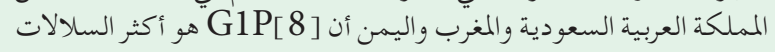

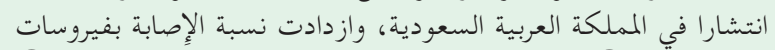

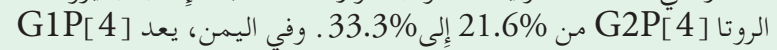

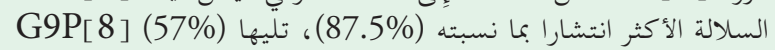

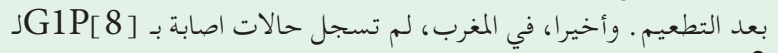

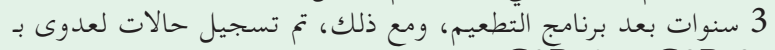

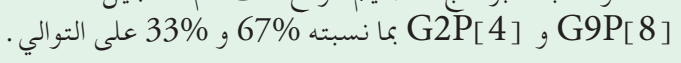

الحاتمة : تبين هذه الدراسة أن فيروسات الروتا والتي تنتشر سلالاتها في بلتي

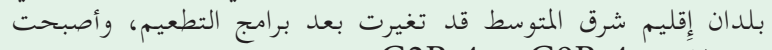

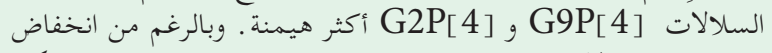

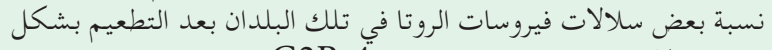

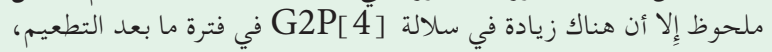

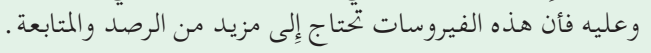

Objective: To detect changes in circulating strains of rotavirus in the Eastern Mediterranean Region (EMR) post rotavirus immunization drive.

Methods: We searched MEDLINE, PubMed, ScienceDirect, and the Cochrane Library and specific database website (Nutrition and Food Sciences) for relevant articles. Our search included websites of a number of relevant organizations in addition to gray literature search. Of the 2198 articles found, we included only 35 studies after excluding irrelevant, ineligible, duplicated, and very low-quality papers.

Results: Thirty pre-vaccination studies reported frequent rotavirus strains among children below 5 years of age. G1P[8] has been identified as the most dominant type prior to vaccination in EMR countries. Five postvaccination studies conducted in 3 countries (Saudi Arabia, Morocco, and Yemen) illustrated that G1P[8] is the most prevalent strain in Saudi Arabia, and the incidence of $\mathrm{G} 2 \mathrm{P}[4]$ has increased from $21.6 \%$ to $33.3 \%$. In Yemen, G1P[4] is the most prevalent strain (87.5\%), followed by G9P[8] (57\%) and G1P[8] (18.5\%). Furthermore, in Yemen, G9P[8] were the most prevalent strains accounting to $57 \%$ and $14 \%$ in G9P [4], post vaccination. Finally, in Morocco, G1P[8] was not reported 3 years post vaccination; however, incidence of G9P [8] was reported at $67 \%$ and G2P[4] at 33\%.

Conclusions: Rotavirus circulating strain prevalence in EMR countries has changed post vaccination, and G9P[8], G2P[4], and G9P[4] have become more dominant. Proportion of rotavirus strains in these countries after vaccination has significantly reduced. There is an increase in circulating strain G2P[4] in the post-vaccination period, which needs further monitoring. PROSPERO registration number CRD42017056887

Saudi Med J 2018; Vol. 39 (8): 755-756 doi: 10.15537/smj.2018.6.21394

From the Laboratory Medicine Department, Faculty of Applied Medical Sciences, Al Baha University, Kingdom of Saudi Arabia.

Address correspondence and reprint request to: Dr. Shaia S. R. Almalki, Laboratory Medicine Department, Faculty of Applied Medical Sciences, Al Baha University, Kingdom of Saudi Arabia. E-mail:almalkishaia@hotmail.com

ORCID ID: https://orcid.org/0000-0002-5899-9035 
$\mathrm{I}$ n 2016, the World Health Organization (WHO) reported that the under-5 mortality caused by rotavirus infection had reduced from 528,000 $(465,000$ $591,000)$ in 2000 to $215,000(197,000-233,000)$ in 2013. Afghanistan and Pakistan were among the top 10 countries in the world attributable for under-5 children mortality. ${ }^{1}$ Despite the availability of rotavirus vaccines in some Eastern Mediterranean Region (EMR) countries, ${ }^{2}$ rotavirus gastroenteritis (RVGE) is still a major cause of significant morbidity and mortality among children under 5 years of age in the region. ${ }^{3}$ According to the WHO, the cause-mortality rate due to rotavirus infection among children under 5 years in EMR countries was $6.5 \%$ of the deaths from all causes in that age group. ${ }^{4}$ There are 2 main rotavirus vaccines that had been administered in the region in the period from 2008 to 2017: Rotarix (the most common type used in the EMR) and Rotateq. Rotarix is a monovalent vaccine that contains one human G1P8 strain, whereas Rotateq is a pentavalent vaccine that contains 4 human strains (G1, G2, G3, and G4) and one bovine strain (G6). ${ }^{5}$ In January 2017, rotavirus immunization was made available in 13 of the 21 EMR countries: Saudi Arabia, Yemen, Morocco, Sudan, Qatar, Bahrain, United Arab Emirates, Djibouti, Pakistan, Jordan, Libya, Iran, and Iraq.

Five countries have included the rotavirus vaccine in their national vaccination program, ${ }^{2}$ while no such data are available for the remaining 8 countries. ${ }^{2}$ In addition, a few countries have their own rotavirus vaccination programs which have not been reported in the WHO databases. ${ }^{2,6-10}$ With the introduction of rotavirus vaccine, the incidence of RVGE has dropped and the under- 5 children morbidity has shifted in the last few years. ${ }^{6-10}$ The 2 approved rotavirus vaccines have reduced the rate of diarrhea-related hospitalization among children under 5 years of age. ${ }^{11}$ The WHO has recommended the worldwide distribution and incorporation of vaccine in national vaccination programs. ${ }^{1}$ It was approved that both vaccines provided acceptable protection against the most prevalent rotavirus strains and the virus could be mutated and ecologically changed post immunization. ${ }^{11}$

There are more than 60 G-P combination rotavirus strains attributable for RVGE in humans, with the most dominant strains (G2P[4], G1P[8], G4P[8],

Disclosure. Authors have no conflict of interests, and the work was not supported or funded by any drug company.
G3P[8], and G9P[8]) representing almost $90 \%$ of circulating strains. ${ }^{11-14}$ For some countries, reports showed that strains have great diversity overtime with some hypotheses linking this diversity to the availability of rotavirus vaccines. ${ }^{15-17}$ It is still to be found whether rotavirus immunization provides immunity against non-vaccine type strains and whether any forced rotavirus strains appear post vaccination. So, this review was conducted to identify the best evidence for any alteration in the rotavirus strain prevalence in the EMR after vaccination.

Methods. Keywords and search strategy. The search strategy for this review includes specific keywords based on rotavirus strains and according to the searched database as shown in Table 1 . There were language restrictions to English in the studies conducted after January 2000 when the searches were run. The searches were repeated immediately before the analysis of this review.

The search strategy and the keywords used for this review have been explained in the summary of search results (Table 1). A flowchart has been used to display the different stages of the systematic review (identification, screening, eligibility, and inclusion), as shown in Figure 1.

Eligibility criteria. We considered all articles published in English and dated after 2000 and before February 2017 for inclusion in this systematic review. We screened articles for the search terms in any fields (2198 articles). The exclusion criteria included duplicity and irrelevant articles based on the titles and abstracts (2060 articles). Furthermore, for other eligible articles (138 articles), we retrieved the full texts for conducting an in-depth study of the rotavirus strain combinations. We excluded irrelevant studies based on the full text of articles to yield the final list that included 35 relevant articles.

Data sources. We searched the following electronicrelated databases: MEDLINE, PubMed, ScienceDirect, and the Cochrane Library (Cochrane Database of Systematic Reviews) and specific database website (Nutrition and Food Sciences). We included websites of relevant organizations, such as WHO and the Centers for Disease Control and Prevention (CDC) in addition to gray literature search. Out of 2198 search results, only 35 studies were included in this systematic review after excluding irrelevant, ineligible, duplicated, and very low-quality papers. The search strategy has been demonstrated in Table 1.

Type of studies. We included only the studies with cross-sectional and surveillance designs in this review. 
Table 1 - Summary of search results.

\begin{tabular}{|c|c|c|c|c|}
\hline Search Engine & Search Terms & Limits activated & Date searched & Papers \\
\hline Cochrane & Rotavirus & & $23^{\text {th }}$ January, 2017 & 4 \\
\hline $\begin{array}{l}\text { PubMed (MEDLINE } \\
\text { (OvidSP), and EMBASE } \\
\text { (OvidSP) }\end{array}$ & $\begin{array}{c}\text { (infant OR children OR under five) AND (EMR OR } \\
\text { Afghanistan OR Bahrain OR Djibouti OR Egypt OR Iran } \\
\text { OR Iraq OR Jordan OR Kuwait OR Lebanon OR Libya } \\
\text { OR Morocco OR Oman OR Pakistan OR Qatar OR Saudi } \\
\text { Arabia OR Somalia OR Sudan OR Syrian Arab Republic } \\
\text { OR Tunisia OR United Arab Emirates OR Yemen) AND } \\
\text { (rotavirus OR rota vaccine) AND (prevalence OR incidence } \\
\text { OR serotype OR genotype OR strain OR epidemiology OR } \\
\text { symptoms) }\end{array}$ & Human & $23^{\text {th }}$ January, 2017 & 222 \\
\hline \multirow[t]{3}{*}{ Sciencedirect } & $\begin{array}{l}\text { (rotavirus AND EMR) OR (rotavirus AND Afghanistan) } \\
\text { OR (rotavirus AND Bahrain) OR (rotavirus AND Djibouti) } \\
\text { OR (rotavirus AND Egypt) OR (rotavirus AND Iran) OR } \\
\text { (rotavirus AND Iraq) OR (rotavirus AND Jordan) }\end{array}$ & $\begin{array}{l}\text { Medicine and } \\
\text { Dentistry } \\
\text { Nursing and } \\
\text { Health Professions } \\
\text { Journals }\end{array}$ & $24^{\text {th }}$ January, 2017 & 759 \\
\hline & $\begin{array}{l}\text { (rotavirus AND Saudi Arabia) OR (rotavirus AND Somalia) } \\
\text { OR (rotavirus AND Sudan) OR (rotavirus AND Syrian } \\
\text { Arab Republic) OR (rotavirus AND Tunisia) OR (rotavirus } \\
\text { AND United Arab Emirates) OR (rotavirus AND Yemen) }\end{array}$ & $\begin{array}{l}\text { Medicine and } \\
\text { Dentistry } \\
\text { Nursing and } \\
\text { Health Professions } \\
\text { Journals }\end{array}$ & $24^{\text {th }}$ January, 2017 & 492 \\
\hline & $\begin{array}{c}\text { (rotavirus AND Kuwait) OR (rotavirus AND Lebanon) OR } \\
\text { (rotavirus AND Libya) OR (rotavirus AND Morocco) OR } \\
\text { (rotavirus AND Oman) OR (rotavirus AND Pakistan) OR } \\
\text { (rotavirus AND Qatar) }\end{array}$ & $\begin{array}{l}\text { Medicine and } \\
\text { Dentistry } \\
\text { Nursing and } \\
\text { Health Professions } \\
\text { Journals }\end{array}$ & $24^{\text {th }}$ January, 2017 & 571 \\
\hline $\begin{array}{l}\text { Nutrition and Food } \\
\text { Sciences }\end{array}$ & Rotavirus AND Strains OR Prevalence AND children & & $25^{\text {th }}$ January, 2017 & 143 \\
\hline $\begin{array}{l}\text { ISI Web of Science and } \\
\text { Conference Proceedings }\end{array}$ & Rotavirus AND Strains & & $23^{\text {th }}-25^{\text {th }}$ & 5 \\
\hline Grey literature search & Rotavirus AND Strains & & $23^{\text {th }}-25^{\text {th }}$ & 2 \\
\hline Total & $\begin{array}{l}\text { Titles and Abstracts examined } \\
\text { Full texts retrieved } \\
\text { Papers included in the review }\end{array}$ & & & $\begin{array}{c}2198 \\
138 \\
35\end{array}$ \\
\hline \multicolumn{5}{|c|}{2 limits activated - humans, child: $0-5$ years } \\
\hline
\end{tabular}

Data extraction. Three researchers independently screened the search results using inclusion criteria. They retrieved the full-text articles of all possibly relevant references selected by either screener. They requested full-text articles and checked for eligibility. They used the reference manager software EndNote X7 to sort the retrieved articles into inclusion and exclusion folders. The search strategy and the selection process of the studies have been detailed using a flowchart (Figure 1).

Two researchers separately extracted data on a prepared form for data extraction. The data extraction form was tested and refined based on a pilot data extraction. In case of disagreement during studies selection or data extraction, the third researcher would review the studies and they reached on a mutual agreement with further discussion and consensus. They then confirmed all data extraction, and in case of discrepancies, cross-checked with the original articles.

Risk of bias (quality) assessment. We appraised the selected studies using the STROBE Statement Checklist for observational studies. The checklist measured the quality of studies, including 1) study setting, 2) sample size, 3) bias, 4) diagnostic test used, and 5) outcome data. Two authors independently judged each domain and classified bias into "high risk," "low risk," and "unclear risk." The third researcher confirmed the judgment. On reaching consensus, studies were divided into "low risk," high risk," and "unclear risk," and the poor-quality studies (with high risk) were excluded from this systematic review (Table 2).

Statistics. Pooled "combined" proportion of rotavirus detection rate was calculated by adding number of cases detected with rotavirus strains from different studies and then divided the total of cases on the total number of subjects included in the reviewed studies. All extracted data from reviewed literature were presented in tabulated form as appropriate. Bar-chart was drawn utilizing Microsoft Excel software (version 2016) for purpose of visual comparison of extracted rotavirus prevalence from reviewed literature. 


\section{6 papers identified through database searching}

after excluding duplicates and irrelevant papers

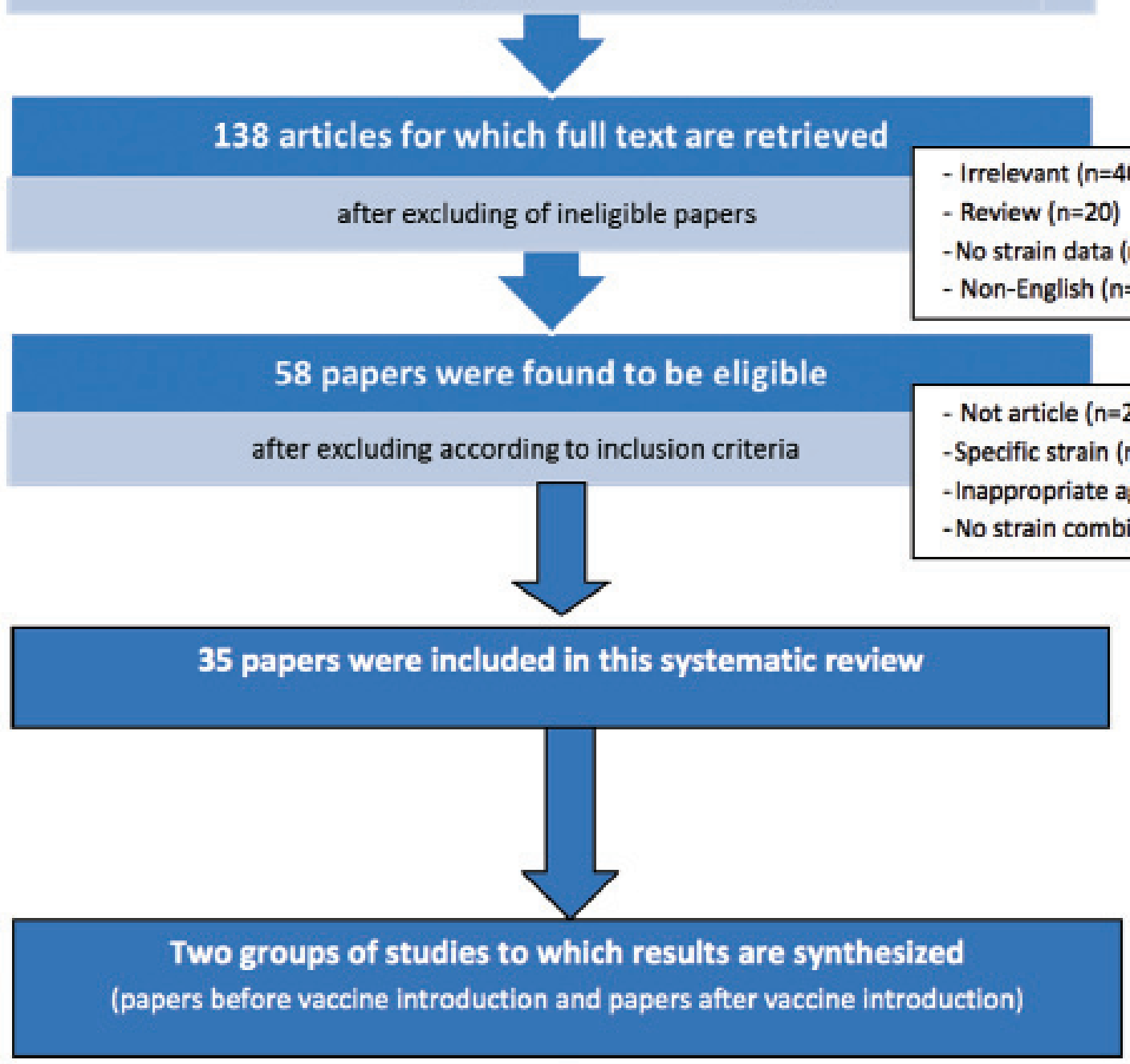

Figure 1 - Flowchart used to display the different stages (identification, screening, eligibility, and inclusion).

The outcome measures. 1) Primary outcome(s): The main outcome was the rotavirus strain prevalence. 2) Secondary outcome(s): These include rotavirus prevalence, rotavirus vaccine used, and rotavirus mixed (G-P) strains circulating pre- and post-vaccination (G1P4, G1P6, G1P8, G2P4, G2P6, G2P8, G3P4, G3P6, G3P8, G4P4, G4P6, G4P8, G9P4, G9P6, G9P8, G12P4, G12P6, G12P8, and any other rare G-P strain combinations).

Results. Of the 35 studies included in this report, 30 studies reported rotavirus strain prevalence before vaccination and 5 reported rotavirus strain prevalence post vaccination. Furthermore, 3 of the 5 postvaccination studies reported information on both pre-vaccine and post-vaccine situation.

Post-vaccination studies included one in Saudi Arabia, ${ }^{18} 2$ in Yemen, ${ }^{19,20}$ and 2 in Morocco. ${ }^{21,22}$ Three of these 5 studies investigated the rotavirus strains as pre- and post-vaccination, 2 in Yemen $^{19,20}$ and one in Morocco. ${ }^{21}$ The studies that investigated the pre-vaccination rotavirus strain prevalence in other EMR countries are from Bahrain, ${ }^{8}$ Egypt, ${ }^{23}$ Kuwait, ${ }^{10}$ 
Table 2 - Quality assessment of the included studies.

\begin{tabular}{|c|c|c|c|c|c|c|}
\hline Country & References & Sample & Design & Study area & Age & Quality \\
\hline Bahrain & 8 & 314 & Surveillance & Single, pediatric hospital-based & Under 5 & Moderate \\
\hline Egypt & 23 & 259 & Surveillance & 2 hospitals in Egypt & Under 5 & High \\
\hline Kuwait & 10 & 172 & Cross-sectional & Al-Amiri and Al-Adan hospitals, Kuwait & Under 5 & High \\
\hline \multirow[t]{5}{*}{ Iran } & 27 & 700 & Cross-sectional & 2 pediatric hospitals in Tehran & Under 5 & High \\
\hline & 24 & 2198 & Surveillance & 5 sentinel hospitals & Under 5 & High \\
\hline & 26 & 618 & Cross-sectional & Hajar Hospital and Shahrekord, Iran & Under 5 & High \\
\hline & 7 & 200 & Cross-sectional & Aboozar hospital & Under 5 & High \\
\hline & 25 & 374 & Cross-sectional & Markaz Tebbi Koudakan Hospital, Tehran & Under 5 & Low \\
\hline \multirow[t]{2}{*}{ Iraq } & 29 & 976 & Surveillance & 3 different cities in Iraq & Under 5 & High \\
\hline & 28 & 260 & Cross-sectional & Erbil Paediatric Hospital & Under 5 & High \\
\hline Jordan & 30 & 368 & Cross-sectional & 2 hospitals, Jordan & Under 5 & High \\
\hline \multirow[t]{3}{*}{ Saudi Arabia } & 31 & 541 & Prospective & Riyadh & Under 5 & High \\
\hline & 32 & 984 & Cross-sectional & 2 hospitals, Maddina. & Under 5 & High \\
\hline & 18 & 850 & Cross-sectional & 5 Saudi hospitals & Under 5 & High \\
\hline Libya & 33 & 520 & Cross-sectional & Al-Jala Children's hospital, Tripoli & Under 5 & High \\
\hline \multirow{5}{*}{ Morocco } & 21 & 1861 & Cross-sectional & 3 hospitals & Under 5 & High \\
\hline & & 533 & Cross-sectional & 3 hospitals & Under 5 & High \\
\hline & 22 & 335 & Surveillance & 4 hospitals & Under 5 & High \\
\hline & 35 & 314 & Surveillance & 4 hospitals & Under 5 & High \\
\hline & 34 & 1,388 & Surveillance & 4 hospitals in Morocco & Under 5 & High \\
\hline \multirow[t]{2}{*}{ Oman } & 36 & 3470 & Surveillance & 11 regional referral hospitals & Under 5 & High \\
\hline & 37 & 310 & Surveillance & 10 selected hospitals and 3 primary health care clinics & Under 5 & High \\
\hline \multirow[t]{5}{*}{ Yemen } & 20 & 5,691 & Surveillance & 2 sentinel hospitals & Under 5 & High \\
\hline & 39 & 290 & Cross-sectional & 2 hospitals & Under 5 & Moderate \\
\hline & 19 & 2334 & A longitudinal observational & Taiz & Under 5 & High \\
\hline & & 1330 & & & & \\
\hline & 38 & 795 & Cross-sectional & Taiz & Under 5 & High \\
\hline \multirow[t]{5}{*}{ Tunisia } & 43 & 621 & $\begin{array}{c}\text { A multicenter prospective } \\
\text { observational }\end{array}$ & 11 sentinel pediatric departments & Under 5 & High \\
\hline & 41 & 2298 & Cross-sectional & 14 different University Hospitals & Under 5 & High \\
\hline & 40 & 982 & Epidemiological survey & Eastern Center of Tunisia & Under 5 & High \\
\hline & 44 & 309 & Epidemiological survey & coastal region & Under 5 & High \\
\hline & 42 & 1127 & Survey & 11 Tunisian cities & Under 5 & High \\
\hline \multirow[t]{5}{*}{ Pakistan } & 49 & 311 & Cross sectional & 2 hospitals & Under 5 & Moderate \\
\hline & 48 & 575 & Surveillance & 2 low-income communities in Karachi & Under 5 & High \\
\hline & 46 & 300 & Cross sectional & Faisalabad region & Under 5 & Moderate \\
\hline & 45 & 1306 & Surveillance & Lahore & Under 5 & High \\
\hline & 47 & 6679 & Cross-sectional & 5 sentinel hospitals & Under 5 & High \\
\hline
\end{tabular}

Iran, ${ }^{7,24-27}$ Iraq, ${ }^{28,29}$ Jordan, $^{30}$ Saudi Arabia, ${ }^{31,32}$ Libya, ${ }^{33}$ Morocco, ${ }^{21,34,35}$ Oman, ${ }^{36,37}$ Yemen, ${ }^{19,20,38,39}$ Tunisia, ${ }^{40-44}$ and Pakistan. ${ }^{45-49}$ We excluded other 8 countries of the EMR from this review (Sudan, Somalia, Afghanistan, Qatar, United Arab Emirates, Djibouti, Syria, and Lebanon) because there were no reports on circulating rotavirus strains among children under 5 years of age. Out of the 21 EMR countries, $13(61.9 \%)$ met the inclusion criteria. Furthermore, only $5(14.3 \%)$ of these 35 studies presented post-vaccination data.

Circulating rotavirus strains were identified in 5 studies, ${ }^{18-22}$ from 3 countries (Saudi Arabia, Yemen, and Morocco) that provided data on rotavirus postvaccination, whereas other EMR countries reported strains pre-vaccination. Studies conducted between 1995 and 2014 were categorized as pre-vaccination studies, whereas studies conducted between 2011 and 2015 were categorized as post-vaccination studies. The inclusion of rotavirus vaccine into national immunization program varies between different countries. Bahrain introduced the vaccination in 2008, while Jordan introduced in 2015; some countries did not introduce this vaccine into their national immunization program because of low endemicity of rotavirus. Morocco has included this vaccination in national immunization program in 2010, Yemen in 2012, and Saudi Arabia in 2013. ${ }^{2}$

The circulating rotavirus strains among children under 5 years of age were reported from 13 included 
Table 3 - Summary of the systematic review findings. ${ }^{2}$

\begin{tabular}{|c|c|c|c|c|c|c|c|c|c|c|c|c|c|c|}
\hline Country & Study & Time & Proportion & G1P $[8]$ & G1P[4] & G2P [8] & G2P[4] & G3P[8] & G3P[4] & G4P [8] & G4P[4] & G9P [8] & G9P[4] & G12P[8] G12P[4] \\
\hline Bahrain & 8 & Pre & 44.8 & 58.8 & & 11.8 & 11.8 & & & & & & & 11.8 \\
\hline Egypt & 23 & Pre & 25.2 & 56.0 & 1.6 & 0.8 & 23.5 & & & & & 1.6 & & \\
\hline Kuwait & 10 & Pre & 43.6 & 58.0 & 1.4 & 1.4 & 5.8 & 2.8 & & 2.8 & & 8.7 & & \\
\hline \multirow[t]{5}{*}{ Iran } & 27 & Pre & 19.0 & 53.4 & 9.2 & & & & & 4.6 & & & & \\
\hline & 24 & Pre & 59.1 & 10.9 & & & 5.5 & 0.9 & & 30.9 & & & & \\
\hline & 26 & Pre & 23.6 & 63.7 & 2.0 & & 8.2 & & & & & & & \\
\hline & 7 & Pre & 36.5 & 80.0 & & & 20 & & & & & & & \\
\hline & 25 & Pre & 24.6 & 59.2 & 1.4 & & 1.4 & & & 4.2 & & 15.5 & & \\
\hline \multirow[t]{2}{*}{ Iraq } & 29 & Pre & 40.0 & 6.0 & 4.0 & 1.0 & 5.0 & & & 3.0 & & & & 3.0 \\
\hline & 28 & Pre & 37.0 & 33.0 & & & 15.0 & & & 21.0 & & 11.0 & & \\
\hline Jordan & 30 & Pre & 49.5 & 56.0 & 1.0 & & 14.0 & 1.0 & & 4.0 & 0.5 & 13.0 & 0.5 & \\
\hline \multirow[t]{3}{*}{ Saudi Arabia } & 31 & Pre & 31.6 & 61.9 & 0.9 & & & 4.4 & & & & 16.8 & & 6.2 \\
\hline & 32 & Pre & 19.0 & 44.0 & & & 20.0 & 4.0 & & & & 11.0 & & 4.0 \\
\hline & 18 & Post & 9.2 & 46.2 & & 2.6 & 25.6 & 3.8 & & 1.3 & & 10.3 & & 5.1 \\
\hline Libya & 33 & Pre & 31.5 & 27.8 & & & 1.7 & & & 2.8 & & 65.9 & & \\
\hline \multirow[t]{5}{*}{ Morocco } & 21 & Pre & 41.0 & 57.0 & & & 15.0 & 0.3 & & 0.6 & & 7.8 & & \\
\hline & & Post & 24.0 & 40.5 & & 4.0 & 21.4 & & & 0.8 & & 15.0 & & \\
\hline & 22 & Post & 26.6 & 51.7 & & 4.5 & 10.1 & & & 3.4 & & 3.4 & & \\
\hline & 35 & Pre & 44.0 & 33.0 & & 0.7 & & & & & & 30.5 & & \\
\hline & 34 & Pre & 42.0 & 55.0 & 0.2 & 0.2 & 9.1 & 0.4 & 0.2 & 0.9 & & 11.3 & & \\
\hline \multirow[t]{2}{*}{ Oman } & 36 & Pre & 49.0 & 3.0 & 3.0 & & 26.0 & & & & & & 3.0 & \\
\hline & 37 & Pre & 57.4 & 19.1 & 6.4 & 0.9 & 8.2 & & & & & & & \\
\hline \multirow[t]{6}{*}{ Yemen } & 20 & Pre & 42.9 & 45.5 & & & 76.5 & & & & & 0 & 0 & \\
\hline & 39 & Post & 18.5 & 87.5 & & & 14.3 & & & & & 57.0 & 14.0 & \\
\hline & 19 & Pre & 27.0 & 55.0 & & & 12.0 & & & & & 21.0 & 1.0 & 1.0 \\
\hline & & Pre & 43.8 & 15.0 & & & 55.0 & & & & & & & \\
\hline & & Post & 10.5 & 31.0 & & & & & & & & 27.5 & & \\
\hline & 38 & Pre & 45.2 & 15.0 & & & 55.0 & & & & & & & \\
\hline \multirow[t]{5}{*}{ Tunisia } & 43 & Pre & 30.3 & 6.5 & & & 0.5 & 24.4 & & 13.3 & & & & \\
\hline & 41 & Pre & 22.4 & 23.0 & & & 24.0 & 23.0 & & 10.0 & 0,6 & 0.6 & & 1.5 \\
\hline & 40 & Pre & 22.0 & 34.0 & 10.0 & & 3.0 & 4.0 & 3.0 & 2.0 & 1 & 2.0 & & \\
\hline & 44 & Pre & 26.2 & 35.7 & & & 4.8 & 2.3 & 4.8 & 2.3 & & & & \\
\hline & 42 & Pre & 24.0 & 34.4 & & & 4.0 & 16.3 & & 8.9 & & 10.3 & & 1.9 \\
\hline \multirow[t]{5}{*}{ Pakistan } & 49 & Pre & 23.8 & 24.3 & & & 24.3 & & & & & 10.8 & & \\
\hline & 48 & Pre & 17.0 & 13.0 & 8.4 & 3.6 & 6.0 & & & 2.0 & & 15.0 & 2.0 & \\
\hline & 46 & Pre & 57.3 & 25.3 & & & & 1.5 & & & & & & \\
\hline & 45 & Pre & 34.0 & 2.3 & 6.2 & 2.3 & 47.8 & & & & & 15.9 & 2.3 & \\
\hline & 47 & Pre & 30.5 & 11.6 & & & 10.4 & & & & & & & \\
\hline
\end{tabular}

countries. The highest prevalence rate pre-vaccination was reported from Iran (59.1\%), ${ }^{24}$ followed by Yemen $(57.4 \%),{ }^{37}$ and Pakistan (57.3\%). ${ }^{46}$ The highest rate post-vaccination was reported from Morocco $(26.6 \%),{ }^{22}$ and $(24 \%),{ }^{21}$ followed by Yemen $(18.5 \%$ and $10.54 \%),{ }^{19,20}$ and Saudi Arabia (9.2\%). ${ }^{18}$ In the 13 countries included, G1P[8] was the most circulated strain pre-vaccination. $7,8,10,18,23,26,29,30,33,34,37,39,42,44$ The same findings were reported at the period immediately after vaccination, since G1P[8] was the most common strain in the 3 countries included: Yemen, ${ }^{20}$ Morocco, ${ }^{22}$ and Saudi Arabia, ${ }^{18}$ which had been altered in the subsequent years after vaccination.
In Saudi Arabia, the studies showed that G1P[8] was not the most common strain combination during pre-vaccination period. G1P[4] was the most common (88\%) followed by G1P[8] (61.9\%). ${ }^{31}$ Kheyami et al, ${ }^{32}$ (2008) showed that G1P[8] was the dominant strain (44\%). Only one available study conducted after vaccination in Saudi Arabia showed that G1P[8] was the predominant strain. ${ }^{18}$

Out of 4 studies conducted in Morocco, 2 prevaccination rotavirus strain, one study was conducted after introduction of the vaccine, and one study compared the situation before and after vaccination. During the pre-vaccination period, G1P[8] was the 


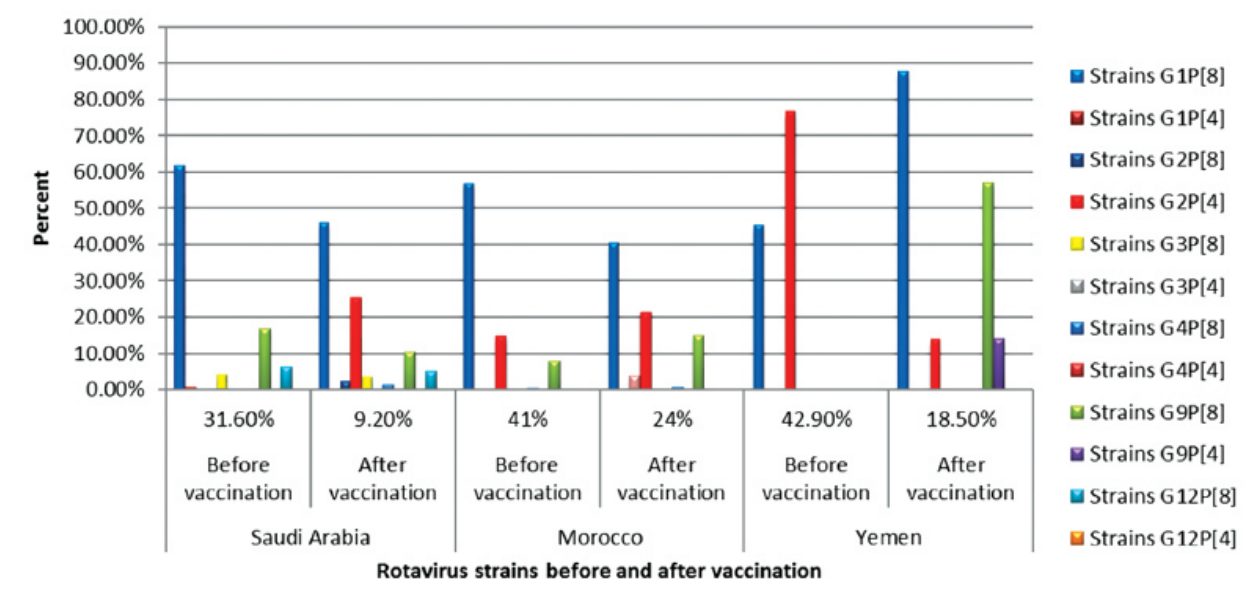

Figure 2 - The circulating Rotavirus strains prior and post vaccination in Saudi Arabia, Morocco and Yemen.

most common strain representing $57 \%,{ }^{21} 33 \%,{ }^{35}$ and $55 \%,,^{34}$ and the same findings were found after introduction of vaccine: $51.7 \%{ }^{22}$ and $40.5 \% .^{21}$ Out of 4 studies conducted in Yemen, 2 studied the rotavirus strain prevalence pre- and post-vaccination, while 2 reported rotavirus only before vaccination. The findings of studies before introduction of vaccine showed that G1P[8] was the most prevalent in the 2 traced studies: $55 \%{ }^{19,38}$ and $12 \% .^{39}$

Another study showed that G2P[4] was the most prevalent (76.6\%) followed by G1P[8] $(45.5 \%),{ }^{20}$ and then after introduction of rotavirus vaccine the same author reported that G1P[4] was the most prevalent $(87.5 \%)$ followed by G9P[8] (57\%) and G1P[8] $(18.5 \%) .{ }^{20}$ The other strain combinations were reported pre- and post-vaccination (Table 3 ). High incidence of G2P[4] was summarized in Table 3 \& Figure 2. After 2 years of rotavirus vaccination program, it was reported that the rates of strain combinations were G1P[8], G2P[4], G9P [8], G12P[8], and G1P[8] dropped from $51 \%$ to $37.1 \%$, while G2P [4] increased from $21.6 \%$ to $33.3 \%{ }^{18}$ (Table 3).

In Morocco, prior to rotavirus vaccination, incidence of G1P [8] was the highest followed by G2P [4], G9P [8], $\mathrm{G} 2 \mathrm{P}[6], \mathrm{G} 4 \mathrm{P}[8]$, and G3P [8]. The rare reported strains were isolated, all of which represented approximately $6 \%$ of rotavirus strains. Stimulatingly, the emergence of G9P [8] strain was the second most common prevalent strain before vaccination $(30.5 \%)$ (Table 3 ).

Both G4P[8] and G3P[8] strains were reported at low rate pre-vaccination. After vaccination, G1P[8] continued to be the most frequent strain followed by G2P[4] and G4P[8]. One year later, G2P[4] strains were the most common, followed by G1P[8], and
G9P [8].

Three years after vaccination, a huge change was reported in rotavirus strains. G1P[8] was not found, but G9P[8] and G2P[4] were found at 67\% and $33 \%$, respectively. ${ }^{21,22}$ In Yemen, G2P[4] strain was the predominant type (55\%), followed by G1P[8] (15\%) post-vaccination. Furthermore, G1P[8] strain was the prevalent strain (31\%), followed by G9P[8] (27.5\%), ${ }^{19}$ and the report from Yemen by Banajeh and Abu Asba (2015) showed that G1P[8] had increased from 45.5\% to $87.5 \%$, while G2P[4] dropped from $76.5 \%$ to only 2 strains post-vaccination. However, G9P [8] and G9P [4] strains were not reported before vaccination, but became more common representing $57 \%$ and $14 \%$, respectively, post-vaccination. ${ }^{20}$

Discussion. The routine follow-up for the efficacy of rotavirus vaccine is essential in all countries that use rotavirus vaccine in their national immunization programs. ${ }^{5}$ This study aimed at identifying any alteration in the rotavirus strain prevalence in EMR countries after the introduction of vaccine in immunization programs.

There are many clinical and epidemiological researches that have examined rotavirus strains before the vaccine introduction. The results of these researches were fully described, especially in EMR countries having high endemicity. ${ }^{6,18,20,26,35,43,49}$ A small number of researches in the EMR (only 5 studies) have investigated the rotavirus strains during post-vaccination period. ${ }^{18-22}$

The pooled proportion of rotavirus strain detection among children under 5 years in EMR countries was $33.23 \%$ (with range from 9.1 to 59.1). In comparison to other regions, the EMR is in the middle between the higher level (45\%) reported in Asia and lower level 
found in Africa (24\%). ${ }^{50-52}$ The findings of this review are similar to reviews of global and other regions on rotavirus strain prevalence as reported earlier. ${ }^{52-54}$ The recent report on the rotavirus detection rate in $\mathrm{WHO}$ regions showed that the rate of detection dropped slightly over the last years in all WHO regions except the Latin American region. The detection rate started to decrease rapidly in 2008, and the rate of rotavirus detection in Northern African countries dropped to $18 \%$ in $2012 .{ }^{55}$ This systematic review related to rotavirus strains among children under 5 years in the EMR countries showed endemicity of rotavirus infection as the leading cause of diarrhea among children.

Recent estimates show that rotavirus among children causes 65,000 deaths every year in the EMR, which can be prevented through an effective rotavirus vaccination program..$^{33}$ The infections are higher among hospitalized children $(40 \%)$ than outpatient children $(23 \%) .{ }^{53}$ Several EMR countries have included rotavirus vaccine in their national vaccination programs since 2008; however, the prevalence of rotavirus is still high in these countries. ${ }^{18-22}$ There is a need for continuous monitoring of rotavirus vaccine effectiveness and any alteration in the rotavirus strain prevalence.

It is important to probe rotavirus strain changes or mutation. This review found 5 studies from 3 EMR countries (Yemen, Saudi Arabia, and Morocco), which provided information on the rotavirus strain prevalence post-vaccination. The diversity of rotavirus strains in these countries has been discussed and explained.

A recent systematic review on the efficacy of rotavirus vaccine in high- and middle-income Latin American countries reported that both rotavirus vaccines protect from rotavirus and this protection is against varies types of rotavirus strains. The rotavirus vaccine introduction could not provide selective pressure on the emergence of rotavirus strains. Previous reports on the effects of rotavirus vaccine showed that the vaccine provided protection against rotavirus strains and did not induce development of new rotavirus strains due to the pressure of the utilized vaccine. ${ }^{56}$ The rotavirus strain distribution in the post-vaccination period showed different circulating strain prevalence compared to pre-vaccination period in EMR countries. An interesting finding was reported from the countries with post-vaccination studies (Saudi Arabia, Morocco, and Yemen), ${ }^{18-22}$ that used Rotarix vaccine. Uncommon and rare rotavirus strain combinations continue to appear and may cause local epidemics, even in countries having immunization programs. Furthermore, strains used in vaccine have been found in both vaccinated and non-vaccinated children, and this is possibly because of vaccine pressure.

During pre-vaccination period, specific rotavirus strains were highly prevalent in some countries with different strains. Detected strain at pre-vaccination period in EMR countries showed that G1P[8] strain was the most prevalent circulating strain in most EMR countries; ${ }^{10,23,26,29-31,34}$ the second most co-dominant circulating strain was G9P[8] followed by G1P[4] strain..$^{20,33,38}$ During post-vaccination period, the 5 studies included have shown that the dominant strains in Saudi Arabia were G1P [8], G9P [8], and G2P [4], ${ }^{18}$ as were G1P[8] and G9P [8] in Morocco and Yemen. ${ }^{19-21} \mathrm{~A}$ report from Saudi Arabia by Al-Ayed et $\mathrm{al}^{18}$ found high distribution of G2P[4] in the post-vaccination period. There was difficulty in detecting G9P [8] and G12P[8] strains because of the low recognition rate of these strains during the period of study. The investigation of the rare strain G2P[4] in countries other than Saudi Arabia using the same vaccine showed contradictory findings. Recent reports showed a large-scale detection of G2P [4] strain during the post-vaccination period, , 17,57-59 which was also observed in countries without rotavirus vaccination program. This is because of natural influences on rotavirus circulating strains $s^{60,61}$ and it is not associated with vaccination.

Furthermore, other regions also reported predominance of rotavirus $\mathrm{G} 2 \mathrm{P}[4]$ during the postvaccination period, including Nicaragua, Brazil, ${ }^{16}$ Colombia, Honduras, Guatemala, and other Latin American countries. ${ }^{62}$ In Yemen, after introduction of rotavirus vaccine (Rotarix) in 2012, ${ }^{2}$ the prevalence of diarrhea among children caused by rotavirus has decreased. ${ }^{20}$ There were 4 studies investigating the rotavirus strains during pre-vaccination and postvaccination periods in Yemen. One study for prevaccination showed that $55 \%$ of the rotavirus strain combinations were G1P[8], followed by G9P[8] (21\%) and G2P[4] (12\%), but these findings were limited because the study was conducted only in one city (Sana'a) in the highlands of Yemen. ${ }^{39}$

Another study, which was conducted in 2 Yemeni cities (Taiz and Aden), included pre- and postvaccination statistics. The findings reported that the predominant strains were G1P[8] (45.5\%) and G2P[4] (76.5\%). There was a new emergence of G9P[8] after Rotarix vaccination, caused by geographical and weather variations. ${ }^{20}$ Banajeh et $\mathrm{al},{ }^{20}$ reported a significant $38.3 \%$ drop in G2 circulating strains post-vaccination, although they were not covered in the Rotarix vaccine. The G1 circulating strain has insignificantly reduced from $41.3 \%$ to $33.3 \%$ after rotavirus vaccination. 
Furthermore, G9 circulating strains significantly became high after vaccination, with the occurrence of new strains including G9P [8] and G9P[4], which were not reported before vaccination. ${ }^{19,20}$ Findings from Yemen studies indicated that differences in prevalent strains of rotavirus occurred independently and were not associated with rotavirus vaccination. Other evidence supports that Rotarix protects against G2P[4], G9P[4], and G9P[8]. ${ }^{19,20}$ In Morocco, the rotavirus vaccine (Rotarix) had been included in the national immunization program in $2010 .^{2}$ A recent study on the effect of Rotarix on rotavirus strains showed a significant reduction in the rotavirus prevalence among children ( $41 \%$ to $24 \%){ }^{21}$ The period after vaccination was characterized by an emergence of a high rate of G2P[4] strain, which was the most circulating strain after 2 years of rotavirus immunization. ${ }^{21}$ G2P[4] strain emergence may be correlated to weather variation and not vaccine pressure; these findings are similar to the report from Yemen. ${ }^{20}$ Same findings of high G2P[4] prevalence have been shown by several non-vaccinated Asian, Latin American, and African countries. ${ }^{63-67}$ Furthermore, G2P[4] has also been shown as the most common circulating strain in non-vaccinated countries in Europe and Central America. ${ }^{68,69}$ Thus, the high rate of $\mathrm{G} 2 \mathrm{P}[4]$ after Rotarix vaccination reported in Morocco and Yemen needs continuous monitoring and full investigation, which could be due to geographical and weather variations and not due to vaccine influences.

Furthermore, G9P[8] strain emerged as the most prevalent strain after 3 years of immunization in Morocco (67\%), followed by G2P[4] strain (33\%). G9P [8] and G2P[4] strains were found to have high prevalence post Rotarix vaccination in other countries. ${ }^{17}$ Emergence of new different strains had also been reported during the pre-vaccination period in Morocco, ${ }^{34}$ and Australia. ${ }^{17}$

Furthermore, the herd immunity after national vaccination programs including rotavirus vaccine could enhance the protection of rotavirus transmission and decrease the rotavirus proportion in the abovementioned countries. However, this systematic study has generalizable findings. It has several limitations such as lack of published studies in the EMR at post-vaccination period and lack of appropriately conducted studies in the EMR countries post rotavirus vaccination, which may lead to underestimation of the prevalent rotavirus strains during post-vaccination period compared to pre-vaccination period. In fact, the 35 studies included with rotavirus strains were from 13 countries out of 21 EMR countries. The inappropriateness of reported data limited the ability to find seasonal influences and related geographic effects of rotavirus distribution.
In conclusion, rotavirus circulating strains in the EMR have been altered post rotavirus vaccination, and G9P[8], G2P[4], and G9P[4] strains became more dominant. However, despite the changes seen in the rotavirus circulating strains post-vaccination, the situation did not show any significant differences due to rotavirus vaccine use. This review showed a significant reduction in rotavirus distribution in EMR countries especially post-vaccination. The change in prevalent strains and increase in circulation of G2P[4] during post-vaccination period need further monitoring.

This systematic review provides details on rotavirus strain prevalence in EMR countries and is a starting point on which prevalent strains in other WHO regions can be evaluated pre- and post-rotavirus vaccination. Moreover, detection of new emergent rotavirus strains post vaccination requires development of rotavirus vaccines currently in use.

Acknowledgement. Special thanks for Dr. Raed Alharbi (Head, Laboratory Medicine Department, Al Baha University, Al Baha, Saudi Arabia) and Dr. Waled Ahmed (Head, Nursing Department Al Baha University) for generous support in data extraction of this systematic review. The author also thanks Dr. Mohammad A. Albanghali (Head, Community Health Department, Albaha University) for his revision of statistics section of this systematic review.

\section{References}

1. World Health Organization. Estimated rotavirus deaths for children under 5 years of age: 2013, 215 000. [Updated 2016; cited 2016]. Available from: http://www.who.int/ immunization/monitoring_surveillance/burden/estimates/ rotavirus/en/

2. World Health Organization. WHO vaccine-preventable diseases: monitoring system 2016 global summary. [Updated 2016; cited 2017]. Available from: http://apps.who.int/ immunization_monitoring/globalsummary/timeseries/ tscoveragerota1.html

3. Khalil I, Colombara DV, Forouzanfar MH, Troeger C, Daoud F, Moradi-Lakeh M, et al. Burden of diarrhea in the Eastern Mediterranean Region, 1990-2013: Findings from the global burden of disease study 2013. Am J Trop Med Hyg 2016; 95 : 1319-1329.

4. World Health Organization. Scaling up the Expanded Programme on Immunization to meet global and regional targets. 2011. Available from: http:/www.who.int/iris/ handle/10665/123037

5. Kollaritsch H, Kundi M, Giaquinto C, Paulke-Korinek M. Rotavirus vaccines: a story of success. Clin Microbiol Infect 2015; 21: 735-743.

6. Shoeib AR, Hull JJ, Jiang B. Rotavirus G and P types in children with acute diarrhea in Cairo, Egypt, 2011-2012. J Egypt Public Health Assoc 2015; 90: 121-124. 
7. Azaran A, Makvandi M, Samarbafzadeh A, Neisi N, Hoseinzadeh M, Rasti M, et al. Study on Rotavirus infection and its genotyping in children below 5 years in South West Iran. Iran J Pediatr 2016; 26: e2080.

8. Musawi MA, Zainaldeen H, Shafi F, Anis S, Deantonio R. Rotavirus gastroenteritis in children under 5 years in the Kingdom of Bahrain: hospital-based surveillance. Clin Epidemiol 2013; 5: 269-275.

9. Valle DA, Antunes GR, de Assis RMS, da Rosa ML. Rotavirus epidemiology before and after vaccine introduction. J Pediatr (Rio J) 2013; 89: 470-476.

10. Marmash RW, Dalwai AK, Szucs G, Molla AM, Pacsa AS, Al-Nakib W, et al. Genotypic characterization of rotaviruses and prevalence of serotype-specific serum antibodies in children in Kuwait. Epidemiol Infect 2007; 135: 1331-1337.

11. Patel MM, Glass R, Desai R, Tate JE, Parashar UD. Fulfilling the promise of rotavirus vaccines: how far have we come since licensure? Lancet Infect Dis 2012; 12: 561-570.

12. Todd S, Page NA, Duncan Steele A, Peenze I, Cunliffe NA. Rotavirus strain types circulating in Africa: review of studies published during 1997-2006. J Infect Dis 2010; 202 (S1 Suppl): S34-S42.

13. Sanchez-Padilla E, Grais RF, Guerin PJ, Steele AD, Burny ME, Luquero FJ. Burden of disease and circulating serotypes of rotavirus infection in sub-Saharan Africa: systematic review and meta-analysis. Lancet Infect Dis 2009; 9: 567-576.

14. Linhares AC, Stupka JA, Ciapponi A, Bardach AE, Glujovsky $\mathrm{D}$, Aruj $\mathrm{PK}$, et al. Burden and typing of rotavirus group $\mathrm{A}$ in Latin America and the Caribbean: systematic review and metaanalysis. Rev Med Virol 2011; 21: 89-109.

15. Grimwood K, Kirkwood CD. Human rotavirus vaccines: too early for the strain to tell. Lancet 2008; 371: 1144-1145.

16. Gurgel RQ, Cuevas LE, Vieira SC, Barros VC, Fontes PB, Salustino EF, et al. Predominance of rotavirus P[4]G2 in a vaccinated population, Brazil. Emerg Infect Dis 2007; 13: 1571-1573.

17. Kirkwood CD, Boniface K, Barnes GL, Bishop RF. Distribution of rotavirus genotypes after introduction of rotavirus vaccines, Rotarix $^{\odot}$ and RotaTeq $^{\odot}$, into the National Immunization Program of Australia. Pediatr Infect Dis J 2011; 30 (1 Suppl): S48-S53.

18. Al-Ayed MS, Asaad AM, Qureshi MA, Hawan AA. Epidemiology of group A rotavirus infection after the introduction of monovalent vaccine in the National Immunization Program of Saudi Arabia. J Med Virol 2017; 89: 429-434.

19. Amood AL-Kamarany M, Al-Areqi L, Mujally A, Alkarshy F, Nasser A, Jumaan AO. Diarrheal diseases hospitalization in Yemen before and after rotavirus vaccination. Scientifica 2016; 2016: doi.org/10.1155/2016/8485417

20. Banajeh SM, Abu-Asba BA. The epidemiology of all-cause and rotavirus acute gastroenteritis and the characteristics of rotavirus circulating strains before and after rotavirus vaccine introduction in Yemen: analysis of hospital-based surveillance data. BMC Infect Dis 2015; 15: 418.

21. Benhafid M, Elomari N, Azzouzi Idrissi M, Rguig A, Gentsch JR, Parashar U et al. Effect of monovalent rotavirus vaccine on rotavirus disease burden and circulating rotavirus strains among children in Morocco. J Med Virol 2015; 87: 944-953.
22. El Qazoui M, Oumzil H, Baassi L, El Omari N, Sadki K, Amzazi $S$ et al. Rotavirus and norovirus infections among acute gastroenteritis children in Morocco. BMC Infect Dis 2014; 14: 300.

23. Matson DO, Abdel-Messih IA, Schlett CD, Bok K, Wienkopff $\mathrm{T}$, Wierzba TF et al. Rotavirus genotypes among hospitalized children in Egypt, 2000-2002. J Infect Dis 2010; 202 (S1 Suppl): S263-S265.

24. Eesteghamati A, Gouya M, Keshtkar A, Najafi L, Zali MR, Sanaei $\mathrm{M}$ et al. Sentinel hospital-based surveillance of rotavirus diarrhea in iran. J Infect Dis 2009; 200 (S1 Suppl 1): S244S247.

25. Farahtaj F, Gallimore CI, Iturriza-Gomara M, Taremi M, Zali MR, Edalatkhah $\mathrm{H}$ et al. Rotavirus VP7, VP4 and VP6 genotypes co-circulating in Tehran, Iran, between 2003 and 2004. Epidemiol Infect 2007; 135: 834-838.

26. Khalili B, Cuevas LE, Reisi N, Dove W, Cunliffe NA, Hart CA. Epidemiology of rotavirus diarrhoea in Iranian children. J Med Virol 2004; 73: 309-312.

27. Modaress S, Rahbarimanesh AA, Edalat R, Sohrabi A, Modarres $\mathrm{S}$, Gomari $\mathrm{H}$ et al. Human rotavirus genotypes detection among hospitalized children, a study in Tehran, Iran. Arch Iran Med 2011; 14: 39-45.

28. Ahmed HM, Coulter JB, Nakagomi O, Hart CA, Zaki JM, Al-Rabaty AA, et al. Molecular characterization of rotavirus gastroenteritis strains, Iraqi Kurdistan. Emerg Infect Dis 2006; 12: 824-826.

29. Ahmed S, Klena J, Albana A, Alhamdani F, Oskoff J, Soliman $\mathrm{M}$ et al. Characterization of human rotaviruses circulating in Iraq in 2008: atypical G8 and high prevalence of P[6] strains. Infect Genet Evol 2013; 16: 212-217.

30. Kaplan NM, Kirby A, Abd-Eldayem SA, Dove W, Nakagomi $\mathrm{T}$, Nakagomi $\mathrm{O}$, et al. Detection and molecular characterisation of rotavirus and norovirus infections in Jordanian children with acute gastroenteritis. Arch Virol 2011; 156: 1477-1480.

31. Aly M, Al Khairy A, Al Johani S, Balkhy H. Unusual rotavirus genotypes among children with acute diarrhea in Saudi Arabia. BMC Infect Dis 2015; 15: 192.

32. Kheyami AM, Nakagomi T, Nakagomi O, Dove W, Hart CA, Cunliffe NA. Molecular epidemiology of rotavirus diarrhea among children in Saudi Arabia: first detection of G9 and G12 strains. J Clin Microbiol 2008; 46: 1185-1191.

33. Abugalia M, Cuevas L, Kirby A, Dove W, Nakagomi O, Nakagomi $T$ et al. Clinical features and molecular epidemiology of rotavirus and norovirus infections in Libyan children. J Med Virol 2011; 83: 1849-1856.

34. Benhafid M, Elomari N, Elqazoui M, Meryem AI, Rguig A, Filali-Maltouf A, et al. Diversity of rotavirus strains circulating in children under 5 years of age admitted to hospital for acute gastroenteritis in Morocco, June 2006 to May 2009. J Med Virol 2013; 85: 354-362.

35. Benhafid M, Youbi M, Klena JD, Gentsch JR, Teleb N, Widdowson MA et al. Epidemiology of rotavirus gastroenteritis among children $<5$ years of age in Morocco during 1 year of sentinel hospital surveillance, June 2006-May 2007. J Infect Dis 2009; 200 (Suppl 1): S70-S75.

36. Al Awaidy SA, Bawikar S, Al Busaidy S, Baqiani S, Al Abedani I, Varghese $\mathrm{R}$ et al. Considerations for introduction of a rotavirus vaccine in Oman: rotavirus disease and economic burden. $J$ Infect Dis 2009; 200 (Suppl 1): S248-S53. 
37. Al Baqlani S, Peenze I, Dewar J, Al Lawati Z, Pearson L, Rupa V et al. Molecular characterization of rotavirus strains circulating in Oman in 2005. J Infect Dis 2010; 202 (Suppl): S258-S262.

38. Al-Badani A, Al-Areqi L, Majily A, Al-Sallami S, Al-Madhagi A, Amood Al-Kamarany M. Rotavirus diarrhea among children in Taiz, Yemen: prevalence-risk factors and detection of genotypes. International Journal of Pediatrics 2014; 2014:doi. org/10.1155/2014/928529

39. Kirby A, Al-Eryani A, Al-Sonboli N, Hafiz T, Beyer M, Al-Aghbari $\mathrm{N}$ et al. Rotavirus and norovirus infections in children in Sana', Yemen. Trop Med Int Health 2011; 16: 680-684.

40. Chouikha A, Fodha I, Noomen S, Bouzid L, Mastouri M, Peenze I et al. Group A rotavirus strains circulating in the eastern center of Tunisia during a ten-year period (1995-2004). J Med Virol 2007; 79: 1002-1008.

41. Mouna BH, Hamida-Rebaï MB, Heylen E, Zeller M, Moussa A, Kacem S, et al. Sequence and phylogenetic analyses of human rotavirus strains: comparison of VP7 and VP8 antigenic epitopes between Tunisian and vaccine strains before national rotavirus vaccine introduction. Infect Genet Evol 2013; 18: 132-144.

42. Moussa A, Ben Hadj Fredj M, Fodha I, BenHamida-Rebaï M, Kacem S, Argoubi A, et al. Distribution of rotavirus VP7 and VP4 genotypes circulating in Tunisia from 2009 to 2014: emergence of the genotype G12. J Med Microbiol 2016; 65: 1028-1037.

43. Soltani M, Bouanene I, Trabelsi A, Harbi A, Hachicha M, Amri F, et al. [Epidemiology of rotavirus gastroenteritis among children under 5 years of age in Tunisia - results of sentinel hospital surveillance 2009 to 2011]. Rev Epidemiol Sante Publique 2012; 60: 473-480.

44. Trabelsi A, Fodha I, Chouikha A, Ben Hadj Fredj M, Mastouri $\mathrm{M}$, Abdelaziz $\mathrm{AB}$ et al. Rotavirus strain diversity in the centre coast of Tunisia from 2000 through 2003. J Infect Dis 2010; 202 (Suppl): S252-S257.

45. Alam MM, Khurshid A, Shaukat S, Suleman RM, Sharif S, Angez $\mathrm{M}$ et al. Epidemiology and genetic diversity of rotavirus strains in children with acute gastroenteritis in Lahore, Pakistan. PLoS One 2013; 8: e67998.

46. Iftikhar T, Butt A, Nawaz K, Sarwar Y, Ali A, Mustafa T et al. Genotyping of rotaviruses detected in children admitted to hospital from Faisalabad Region, Pakistan. J Med Virol 2012; 84: 2003-2007.

47. Kazi AM, Warraich GJ, Qureshi S, Qureshi H, Khan MM, Zaidi AK; members of the Pakistan Rotavirus Study Group. Sentinel hospital-based surveillance for assessment of burden of rotavirus gastroenteritis in children in Pakistan. PLoS One 2014; 9: e108221.

48. Qazi R, Sultana S, Sundar S, Warraich H, un-Nisa T, Rais A et al. Population-based surveillance for severe rotavirus gastroenteritis in children in Karachi, Pakistan. Vaccine 2009; 27 Suppl 5: F25-F30.

49. Tamim S, Hasan F, Matthijnssens J, Sharif S, Shaukat S, Alam MM et al. Epidemiology and phylogenetic analysis of VP7 and VP4 genes of rotaviruses circulating in Rawalpindi, Pakistan during 2010. Infect Genet Evol 2013; 14: 161-168.
50. Bresee J, Fang ZY, Wang B, Nelson EA, Tam J, Soenarto Y et al.; Asian Rotavirus Surveillance Network. First report from the Asian rotavirus surveillance network. Emerg Infect Dis 2004; 10: 988-995.

51. Cunliffe NA, Kilgore PE, Bresee JS, Steele AD, Luo N, Hart CA et al. Epidemiology of rotavirus diarrhoea in Africa: a review to assess the need for rotavirus immunization. Bull World Health Organ 1998; 76: 525-537.

52. Malek MA, Teleb N, Abu-Elyazeed R, Riddle MS, Sherif $\mathrm{ME}$, Steele $\mathrm{AD}$, et al. The epidemiology of rotavirus diarrhea in countries in the Eastern Mediterranean Region. Journal of Infectious Diseases 2010; 202 (Supp 1): S12-S22.

53. Parashar UD, Hummelman EG, Bresee JS, Miller MA, Glass RI. Global illness and deaths caused by rotavirus disease in children. Emerg Infect Dis 2003; 9: 565-572.

54. Dóró R, László B, Martella V, Leshem E, Gentsch J, Parashar $\mathrm{U}$, et al. Review of global rotavirus strain prevalence data from six years post vaccine licensure surveillance: is there evidence of strain selection from vaccine pressure? Infect Genet Evol 2014; 28: 446-461.

55. Tate JE, Burton AH, Boschi-Pinto C, Parashar UD, Network WHOCGRS, Agocs M, et al. Global, regional, and national estimates of rotavirus mortality in children $<5$ years of age, 2000-2013. Clinical Infectious Diseases 2016; 62 (Suppl 2): S96-S105.

56. Leshem E, Lopman B, Glass R, Gentsch J, Bányai K, Parashar $\mathrm{U}$ et al. Distribution of rotavirus strains and strain-specific effectiveness of the rotavirus vaccine after its introduction: a systematic review and meta-analysis. Lancet Infect Dis 2014; 14: 847-856.

57. Zeller M, Rahman M, Heylen E, De Coster S, De Vos S, Arijs I et al. Rotavirus incidence and genotype distribution before and after national rotavirus vaccine introduction in Belgium. Vaccine 2010; 28: 7507-7513.

58. Paulke-Korinek M, Kollaritsch H, Aberle SW, Zwazl I, Schmidle-Loss B, Vécsei A, et al. Sustained low hospitalization rates after four years of rotavirus mass vaccination in Austria. Vaccine 2013; 31: 2686-2691.

59. Payne DC, Boom JA, Staat MA, Edwards KM, Szilagyi PG, Klein EJ et al. Effectiveness of pentavalent and monovalent rotavirus vaccines in concurrent use among US children <5 years of age, 2009-2011. Clin Infect Dis 2013; 57: 13-20.

60. Steyer A, Sagadin M, Kolenc M, Poljšak-Prijatelj M. Molecular characterization of rotavirus strains from pre- and postvaccination periods in a country with low vaccination coverage: the case of Slovenia. Infect Genet Evol 2014; 28: 413-425.

61. Bar-Zeev N, Kapanda L, Tate JE, Jere KC, Iturriza-Gomara M, Nakagomi O, et al. VacSurv Consortium. Effectiveness of a monovalent rotavirus vaccine in infants in Malawi after programmatic roll-out: an observational and case-control study. Lancet Infect Dis 2015; 15: 422-428.

62. Bucardo F, Nordgren J. Impact of vaccination on the molecular epidemiology and evolution of group A rotaviruses in Latin America and factors affecting vaccine efficacy. Infect Genet Evol 2015; 34: 106-113.

63. Page NA, Steele AD. Antigenic and genetic characterization of serotype G2 human rotavirus strains from South Africa from 1984 to 1998. J Med Virol 2004; 72: 320-327. 
64. Khamrin P, Peerakome S, Tonusin S, Malasao R, Okitsu S, Mizuguchi $\mathrm{M}$, et al. Changing pattern of rotavirus $\mathrm{G}$ genotype distribution in Chiang Mai, Thailand from 2002 to 2004: decline of G9 and reemergence of G1 and G2. J Med Virol 2007; 79: 1775-1782.

65. Rahman M, Sultana R, Ahmed G, Nahar S, Hassan ZM, Saiada F et al. Prevalence of G2P[4] and G12P[6] rotavirus, Bangladesh. Emerg Infect Dis 2007; 13: 18-24.

66. Vizzi E, Piñeros O, González GG, Zambrano JL, Ludert JE, Liprandi F. Genotyping of human rotaviruses circulating among children with diarrhea in Valencia, Venezuela. $J$ Med Virol 2011; 83: 2225-2232.
67. Ferreira MS, Xavier MP, Tinga AC, Rose TL, Fumian TM, Fialho AM, et al. Assessment of gastroenteric viruses frequency in a children's day care center in Rio De Janeiro, Brazil: a fifteen year study (1994-2008). PLoS One 2012; 7: e33754.

68. Patel MM, de Oliveira LH, Bispo AM, Gentsch J, Parashar UD. Rotavirus P[4]G2 in a vaccinated population, Brazil. Emerg Infect Dis 2008; 14: 863-865.

69. Iturriza-Gomara M, Dallman T, Bányai K, Böttiger B, Buesa J, Diedrich S, et al. Rotavirus surveillance in Europe, 2005-2008: web-enabled reporting and real-time analysis of genotyping and epidemiological data. J Infect Dis 2009; 200 Suppl 1: S215-S221. 